\title{
DIFFUSIVE PROPERTIES OF ALGINATE BIOSORBENTS
}

\author{
WŁAŚCIWOŚCI DYFUZYJNE BIOSORBENTÓW ALGINIANOWYCH
}

\begin{abstract}
Effective diffusion coefficients for different heavy-metal salts: $\mathrm{Cu}, \mathrm{Cd}, \mathrm{Zn}, \mathrm{Cr}, \mathrm{Pb}$ in calcium alginate beads were determined. Their values depended on the metal type, anion from the metal salt, and the alginate content in the beads. The results of calculations indicate a decrease in the values of $D_{e}$, caused by an increase in the alginate content in the alginate sorbent beads. This is in agreement with the mechanism of the diffusion process taking place in porous carriers. Experimental data were found to be in good agreement with the mathematical model, as indicated by high values of the correlation coefficient.
\end{abstract}

Keywords: effective diffusion coefficients, heavy-metal salts, calcium alginate beads

\section{Introduction}

Many kinds of industrial liquid waste, such as those arising in the metallurgic, chemical, mining, tanning industries, are rich in toxic heavy metals [1-3] having a proven harmful effect on many forms of life. Of these, lead, cadmium, copper, mercury and zinc are known to be especially harmful to man and the environment [4].

Heavy metals are eliminated from liquid waste by means of a number of techniques, such as: chemical precipitation, ion exchange, reverse osmosis, membrane techniques, and adsorption [5, 6]. In spite of being highly efficient, the above methods have certain disadvantages, including: high cost, generation of large volumes of sediment, problems with recycling and with the reuse of adsorbents or ion exchangers [5-7]. This encourages searching for alternative sorbents. Biosorption on materials of natural origin seems to be providing the most prospective results: in addition to being highly efficient, it enables elimination of the entire content of metal ions, even if they are present at very low concentrations in the liquid waste. Biosorption is based on sorbents in the form of readily available materials of natural origin or on waste products arising in industry or agriculture: such sorbents have a high sorption capacity and are rather inexpensive, in comparison with high-priced synthetic sorbents.

Pollutants do not only include toxic, cancerogenic and mutagenic metals (such as chromium, lead, mercury), but also metals of economic value (such as silver, gold,

\footnotetext{
${ }^{1}$ Faculty of Chemical Technology and Engineering, University of Technology and Life Sciences, ul. Seminaryjna 3, 85-326 Bydgoszcz, Poland, phone +48 523749049

*Corresponding author: sylwia.kwiatkowska@utp.edu.pl
} 
platinum), therefore, possibilities of their recovery have become another important issue. Once again, biosorption has appeared to be an efficacious though low-cost solution for the recovery of heavy metals. For the above reasons, sorption on materials of natural origin has become the subject of extensive studies (described, for instance, in [8-21]). The studies have demonstrated that marine algae, which are acquired at a rather low cost, have a considerable sorption capacity.

The sorption properties of algal biomass are connected with its biopolymeric content, therefore, such biopolymers could be used for the biosorption of heavy metals after being separated. The cell walls of numerous species of brown algae (including Macrocystis, Laminaria, Ectocarpus, Chorda, Fucus, Nereocystis, Alaria) are built of alginates macromolecular polysaccharides containing uronic acid radicals. This group of compounds include alginic acid - a linear copolymer of two uronic acids (D-mannuronic and L-guluronic acids), connected by $\beta-1,4$ glycoside bonds (Fig. 1). The sorption properties of alginates have been investigated since 1990's [9-11, 15, 22-33].

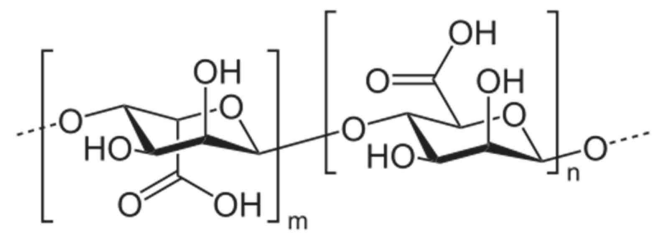

Fig. 1. Structure of alginic acid

Major advantages of the use of alginates as biosorbents include: efficiency, selectivity, and non-toxicity. Being readily available in large volumes because of their numerous applications, they are also low-priced. Alginates are biopolymers with high sorption capacity for heavy metals, even at low concentrations of the metals in solutions. Their sorption capacities are much higher than those of commonly used metal sorbents, such as active carbon. A very simple technology provides a biosorbent in the form of beads, which are easily separated from the sorbate solution. Moreover, alginate sorbents have the added advantage of being reusable after regeneration (typically, by means of a dilute acid solution) [27] with a simultaneous recovery of metals. Their other advantages also include: biodegradability, hydrophilicity and the presence of carboxylic groups [28]. Owing to all these advantages, alginates are regarded as the most-promising category of biosorbents of heavy metals $[9,10,29]$.

The alginate biosorbents are typically prepared in the form of spherical beads of calcium alginate. In aqueous solutions, heavy metal ions show higher affinity and displace calcium ions, and are combined with the alginates. Sorption of metals takes place throughout the structure of the alginate beads, therefore, they can be regarded as a porous ion exchanger of high permeability and capacity [25]. Moreover, they can be applied in identical process and equipment solutions as ion exchangers.

The sorption of metal ions on alginates takes place at a very fast rate and is only limited by diffusion phenomena. Therefore, according to the commonly accepted belief, the rate of sorption with this type of sorbent is limited by internal diffusion. In order to use the quantitative approach to the diffusive-mass movement within the porous beads having a complicated geometrical structure, the notion of effective diffusion coefficient $D_{e}$ has 
been introduced. Since the rate of sorption on alginate beads is determined by the rate of diffusion in the sorbent pores, it is essential to know the effective diffusion coefficient to design the equipment.

The effective diffusion coefficient $D_{e}$ is connected with the diffusion coefficient for highly dilute aqueous solution $D_{a q}$ by the following relationship:

$$
D_{e}=\frac{D_{a q} \cdot \beta}{\tau}
$$

The tortuosity factor $\tau$ in the relationship takes into account the irregular shape, tortuosities, and variable bead pore sizes. Its values are typically in the range from 1 to 3 and can be found if porosity $\beta$ is known.

In the case of alginate gels, it is convenient to use the diffusion retardation coefficient $\varphi$ :

$$
\varphi=\frac{D_{e}}{D_{a q}}=\frac{\beta}{\tau}
$$

The value of the diffusion retardation coefficient is preferably not higher than 1 ( $\varphi=1$ means that $D_{e}=D_{a q}$; and $\varphi>1$ means that $D_{e}>D_{a q}$ ).

The rate of diffusion has historically been found from changes in sorbate concentrations in the solution in the course of the sorption process. Measurements of the diffusion coefficient can be made in either the open or the closed system. The closed system is more often used because of its simplicity and a much greater abundance of reference material for the diffusion coefficients, found for that system previously. Measurements of $D_{e}$ can be performed regardless of the sorption process, by measuring the rate of diffusion from the beads into the solution. If, during the experiments, diffusion is accompanied by sorption, then the effective coefficient of diffusion in carriers is usually found using the shrinking core model (SCM) $[23,30]$ or the linear absorption model (LAM) $[9,22,30]$.

It should be noted that the effective diffusion coefficient calculating by SCM or by LAM method will provide different values of $D_{e}$. Moreover, LAM will fail in the case of low concentrations of metals in solution [9]. The SCM and LAM methods often provide unsatisfactory results (for instance, the calculated value of $D_{e}$ is higher than the effective diffusion coefficient of the same metal in water), moreover, they are connected with the use of labor-consuming procedures in measuring the metal concentrations.

The known calculation models have had numerous disadvantages, therefore, a new method of determination of the effective diffusion coefficient was proposed [31]. Known as the conductometric method, it is based on measuring changes in the metal-salt solution conductivity (which depends on the solution's concentration) and correlating them with the effective diffusion coefficient.

The main objectives of this research work are: (i) preparation calcium alginate beads from sodium alginate solution, (ii) determine by the conductometric method the effective diffusion coefficient for different heavy-metal salts: $\mathrm{Cu}, \mathrm{Cd}, \mathrm{Zn}, \mathrm{Cr}, \mathrm{Pb}$ in calcium alginate beads, (iii) determine the effect of the metal type, anion from the metal salt and the alginate content in the beads on the $D_{e}$ value. 


\section{Materials and methods}

\section{Reagents}

The alginate beads were made of the sodium alginate from KELCO. Nine different heavy-metal salts were examined: $\mathrm{CuCl}_{2}, \mathrm{CuSO}_{4}, \mathrm{CdCl}_{2}, \mathrm{CdSO}_{4}, \mathrm{ZnCl}_{2}, \mathrm{ZnSO}_{4}, \mathrm{Zn}\left(\mathrm{NO}_{3}\right)_{2}$, $\mathrm{Pb}\left(\mathrm{NO}_{3}\right)_{2}, \mathrm{Cr}\left(\mathrm{NO}_{3}\right)_{2}$.

\section{Preparation of the alginate beads}

Calcium alginate beads were prepared by dropwise addition of a viscous, aqueous sodium alginate solution to $0.05 \mathrm{M}$ of $\mathrm{CaCl}_{2}$ solution. All the beads were prepared in the same way, only the concentration of the aqueous solution of sodium alginate was varied. During the gelation process, the sodium alginate reacted with the $\mathrm{Ca}$ ion from the $\mathrm{CaCl}_{2}$ solution and a cross-linked Ca-alginate was formed. The gelation process was continued for $0.5 \mathrm{~h}$. The beads were then placed in a new $0.05 \mathrm{M}$ portion of $\mathrm{CaCl}_{2}$ for 24 hours to establish an equilibrium between the calcium ions that remained in the solution and those adsorbed by the beads. The resultant beads differed in their alginate gel contents (from 1.3 to $6.1 \mathrm{wt} . \%$ ). The beads were kept in the refrigerator.

The beads were washed with distilled water prior to analysis to make sure the bead pores contained no calcium ions, otherwise, the solution's conductivity could be affected. The beads were then saturated with a selected heavy-metal salt for 24 hours. A $0.1 \mathrm{M}$ solution of the selected heavy-metal salt solution was prepared and a suitable amount of calcium alginate beads was immersed in it. The solution was stirred with a magnetic stirrer. Conductivity of metal salts was determined using the microcomputer conductometer model CPC-551 from ELMETRON. All the experiments were performed at a constant $\mathrm{pH}$ of the solution (5.0) into which the heavy-metal salts diffused, and a constant temperature of $25 \pm 0.5^{\circ} \mathrm{C}$.

\section{The conductometric method for determination of effective diffusion coefficient}

The LAM and SCM methods are based on the diffusion of metal ions from the solution into the beads and their sorption therein; therefore, the coefficient calculated according to LAM and SCM relates to the diffusion of the given metal ions. On the other hand a reversed situation takes place in the conductometric method: the biosorbent beads are saturated with the test metal salt and dropped into distilled water, where diffusion of the metal salt molecules from the bead pores into the solution containing the beads takes place. An increase in the metal salt content of the solution leads to an increase in the solution's conductivity. In the conductometric method, conductivity of the solution into which the test metal salts diffuse is measured. The conductivity varies with the effective diffusion coefficient. The experiment is carried out for a diffusion in the closed system.

In modeling diffusion of the metal salts from the alginate bead pores into the solution, it was assumed that:

1. The alginate beads are spheres with a radius $R$.

2. The total volume of the beads is a sum of the solid volume and the pore volume.

3. During the diffusion, the pores are entirely filled with the aqueous solution of the metal salt.

4. Mass transport takes place only due to diffusion within the pores.

5. The metal salt concentration in water is uniform (the solution is homogeneous). 
6. The liquid volume does not change.

7. Desorption of the metal ions from the alginate beads does not take place.

The metal salt diffusion in the alginate beads is a non-stationary process and, assuming that the effective diffusion coefficient is a constant value, it can be described with Fick's second equation. When the homogeneous alginate beads are spherical, the general mass balance for the diffusion of substances in the spherical beads (for non-stationary state) takes the following form:

$$
\frac{\partial C_{S}}{\partial t}=D_{e}\left(\frac{\partial^{2} C_{S}}{\partial r^{2}}+\frac{2}{r} \frac{\partial C_{S}}{\partial r}\right)
$$

where $C_{S}$ is sorbate concentration in sorbent pores at time $t ; r$ is bead radial coefficient; and $t$ is time.

If $N$ beads which contain the dissolved substance are immersed in a well stirred solution containing no sorbate and has a strictly defined volume, then the following initial and boundary conditions apply:

$$
\begin{array}{lll}
t=0 & 0<r<R & C_{S}=\text { const } \\
t=0 & r>R & C_{L}=0 \\
t>0 & r=0 & \frac{\partial C_{s}}{\partial r}=0 \\
t>0 & r=R & V_{L} \frac{\partial C_{L}}{\partial t}=\left.K A_{s} D_{e} \frac{\partial C_{S}}{\partial r}\right|_{r=R}
\end{array}
$$

where: $A_{s}$ - biosorbent bead area, $C_{L}$ - sorbate concentration in solution at time $t$, $K$ - partition ratio, $R$ - sorbent bead radius, $V_{L}$ - volume of the solution which contains the sorbate.

Assuming that the sorbate is uniformly distributed within the bead and the beads are in equilibrium with the liquid phase, the rate of the sorbate's diffusion from the sorbent beads into the solution is expressed by the following equation, describing the substrates' diffusion outside the sphere in the closed system [34]:

$$
C_{L}=\left(\frac{C_{S 0}}{1+\alpha}\right)\left\{1-\sum_{n=1}^{\infty} \frac{6 \alpha(\alpha+1)}{9+9 \alpha+q_{n}^{2} \alpha^{2}} \exp \left(-q_{n}^{2} \frac{D_{e} t}{R^{2}}\right)\right\}
$$

Where $q_{n}$ represents positive, non-zero roots of equation:

$$
\operatorname{tg} q_{n}=\frac{3 q_{n}}{3+\alpha q_{n}^{2}}
$$

and parameter $\alpha$ is defined by equation:

$$
\alpha=\frac{3 V_{L}}{4 N \pi R^{3} K}
$$

$C_{\infty}$ (the sorbate's equilibrium concentration in the solution) is linked with $C_{S 0}$ (sorbate's concentration in the beads for $t=0$ ) as follows:

$$
C_{\infty}=\frac{C_{S 0}}{(1+\alpha)}
$$


therefore, equation (4) can be described as follows:

$$
\frac{C_{L}}{C_{\infty}}=1-\sum_{n=1}^{\infty} \frac{6 \alpha(1+\alpha)}{9+9 \alpha+\alpha^{2} q_{n}^{2}} \cdot \exp \left(-q_{n}^{2} \frac{D_{e} t}{R^{2}}\right)
$$

By selecting suitable experimental conditions ( $\alpha \geq 100$, which means that the sorbent sample volume is at least 100 times as small as that of distilled water), it is possible to simplify equation (8) into the form which was derived for the open system (thus avoiding the troublesome calculation of the consecutive values of $q_{n}$ ):

$$
\frac{C_{L}}{C_{\infty}}=1-\frac{6}{\pi^{2}} \sum_{n=1}^{\infty} \frac{1}{n^{2}} \cdot \exp \left(-\frac{D_{e} n^{2} \pi^{2} t}{R^{2}}\right)
$$

In the new, conductometric method, determination of the effective diffusion coefficient is based on measurements of conductivity of the solution into which the sorbate diffuses; therefore, assuming that dependence of conductivity on concentration is linear, the following equation is obtained (by transforming the non-stationary diffusion equation):

$$
\frac{P_{t}}{P_{\infty}}=1-\frac{6}{\pi^{2}} \sum_{n=1}^{\infty} \frac{1}{n^{2}} \exp \left(\frac{-D_{e} n^{2} \pi^{2} t}{R^{2}}\right)
$$

where: $P_{t}$ - conductivity of the solution after the time $t, P_{\infty}$ - conductivity of the solution after the time $\infty$.

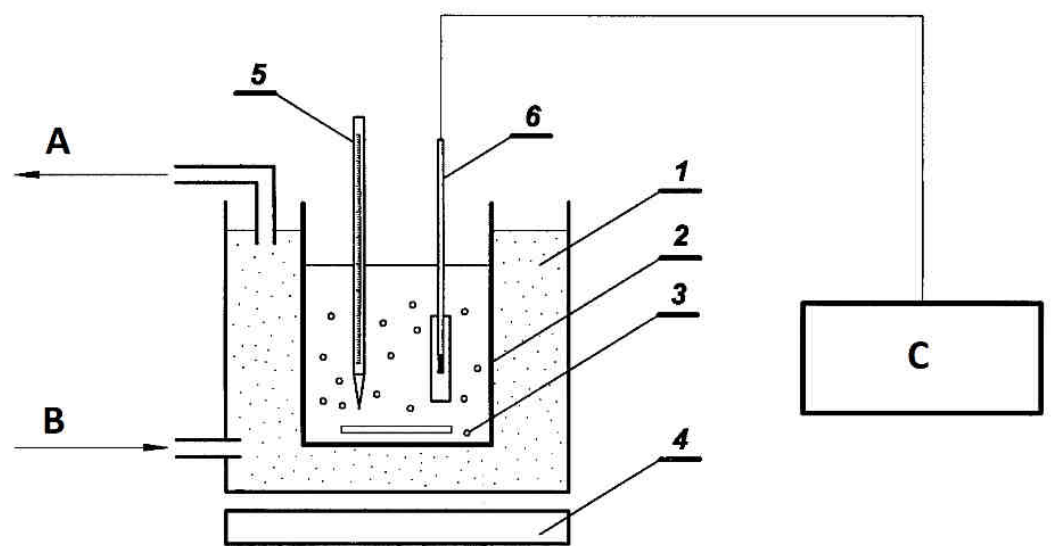

Fig. 2. Setup for determination of effective diffusion coefficient: A - to thermostat, B - from thermostat, C - conductometer with electrode (6), thermostated water jacket (1), beaker containing distilled water (2), alginate beads (3), magnetic stirrer (4), thermometer (5)

A strictly defined sample of alginate beads, saturated with the test metal salt was placed in a beaker filled with distilled water. The contents of the beaker was thermostated and stirred vigorously to eliminate external diffusion resistance and provide an ideal mixing in the system. The metal salt molecules in the sorbent pores diffused into distilled water and the process rate was determined by the effective diffusion coefficient. An increase in the metal ion concentration in the solution was observed to lead to an increase in conductivity, as measured with the conductometer. The sorbent sample volume was more than 100 times 
as small as that of distilled water and conductivity was in linear dependence on concentration, therefore, the effective diffusion coefficient was calculated using equation (10). The amount of the beads, to be used for the test, depended on their diameter. After being saturated with the metal salt, the beads, of which the total volume was not higher than $1 \mathrm{~cm}^{3}$, were dropped in $100 \mathrm{~cm}^{3}$ of distilled water while the magnetic stirrer and a stopper were started. A constant temperature of $25 \pm 0.5{ }^{\circ} \mathrm{C}$ was maintained throughout the experiment. After a defined time $(1,2,3,4,5,10,15,20,30,40,50,60 \mathrm{~min}$, etc., until the value of conductivity was constant), the solution's conductivity was measured.

The setup for determination of the effective diffusion coefficient is shown in Figure 2. It was composed of a $120 \mathrm{~cm}^{3}$ beaker (2) containing distilled water and alginate beads (3), saturated with the test metal salt. A thermostated water jacket (1), magnetic stirrer (4), thermometer (5), and conductometer with electrode (6).

\section{Results and discussion}

Experiments were carried out which confirmed that dependence of the solution's conductivity on the given test-metal salt concentration is linear, and an analysis was carried out which enabled the authors to find that satisfactory accuracy of the results is obtained by using the initial 6 terms of equation (10) for determination of the effective diffusion coefficient for the metal salt diffusion in the calcium alginate beads.

After measuring conductivity of the solution into which the test metal salt ions diffused from the beads, the measurement data were used for determination of the effective diffusion coefficient. The coefficient was calculated from equation (10), using the Levenberg-Marquardt non-linear regression optimization procedure, incorporated in the SLIDE WRITE Plus software.

A typical dependence $P_{t} / P_{\infty}$ on the process duration is shown in Figure 3.

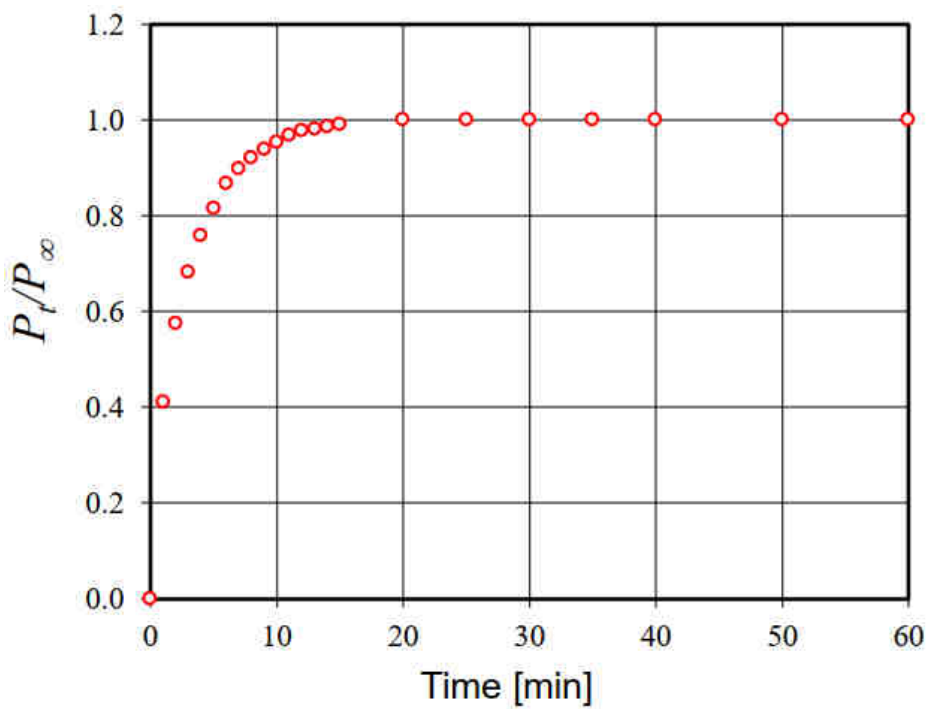

Fig. 3. Dependence of $P_{t} / P_{\infty}$ on the process duration for diffusion of cadmium sulfate from alginate beads with a dry weight of $1.5 \%$ 
The value of effective diffusion coefficient depends on temperature and the alginate content in the biosorbent beads. According to the mechanism of diffusion in porous carriers, an increase in the alginate content in the beads leads to lower values of $D_{e}$. On the other hand, an increase in the process temperature contributes to an increase in the values of the effective diffusion coefficient.

Sulfates, chlorides and nitrates of 5 heavy metals: $\mathrm{Cu}, \mathrm{Cd}, \mathrm{Zn}, \mathrm{Cr}$ and $\mathrm{Pb}$, were examined. The diffusion coefficients of all the heavy-metal salts for a highly dilute aqueous solution $\left(D_{a q}\right)$ for a temperature of $25^{\circ} \mathrm{C}$ were calculated using the Nernst equation.

\section{Copper(II) salt diffusion}

The effective diffusion coefficients, correlation coefficients, and retardation coefficients for copper chloride and sulfate are shown in Table 1. High correlation coefficients were obtained, which indicates good agreement between the experimental data and the mathematical model.

Table 1

Dependence of effective diffusion coefficient on alginate content in beads for copper salts

\begin{tabular}{|c|c|c|c|}
\hline $\begin{array}{c}\text { Alginate content } \\
\text { in beads } \\
\text { [wt. } \%]\end{array}$ & $\begin{array}{c}\text { Effective diffusion } \\
\text { coefficient } \\
\boldsymbol{D}_{\boldsymbol{e}} \cdot \mathbf{1 0}^{\mathbf{9}}\left[\mathbf{m}^{\mathbf{2}} / \mathbf{s}\right]\end{array}$ & $\begin{array}{c}\text { Correlation } \\
\text { coefficient } \\
\boldsymbol{r}^{\mathbf{2}}\end{array}$ & $\begin{array}{c}\text { Retardation coefficient } \\
\boldsymbol{f}=\frac{\boldsymbol{D}_{\boldsymbol{e}}}{\boldsymbol{D}_{a q}}\end{array}$ \\
\hline \multicolumn{5}{|c|}{$\mathrm{CuCl}_{2}\left(D_{a q}=1.29 \cdot 10^{-9} \mathrm{~m}^{2} / \mathrm{s}\right)$} \\
\hline 1.3 & 0.99 & 0.991 & 0.77 \\
\hline 2.6 & 0.91 & 0.993 & 0.70 \\
\hline 3.5 & 0.88 & 0.994 & 0.68 \\
\hline 6.1 & 0.85 & 0.984 & 0.66 \\
\hline \multicolumn{5}{|c|}{$\mathrm{CuSO}_{4}\left(D_{a q}=0.87 \cdot 10^{-9} \mathrm{~m}^{2} / \mathrm{s}\right)$} \\
\hline 1.5 & 0.52 & 0.986 & 0.59 \\
\hline 3.7 & 0.45 & 0.987 & 0.52 \\
\hline 5.7 & 0.41 & 0.985 & 0.47 \\
\hline
\end{tabular}

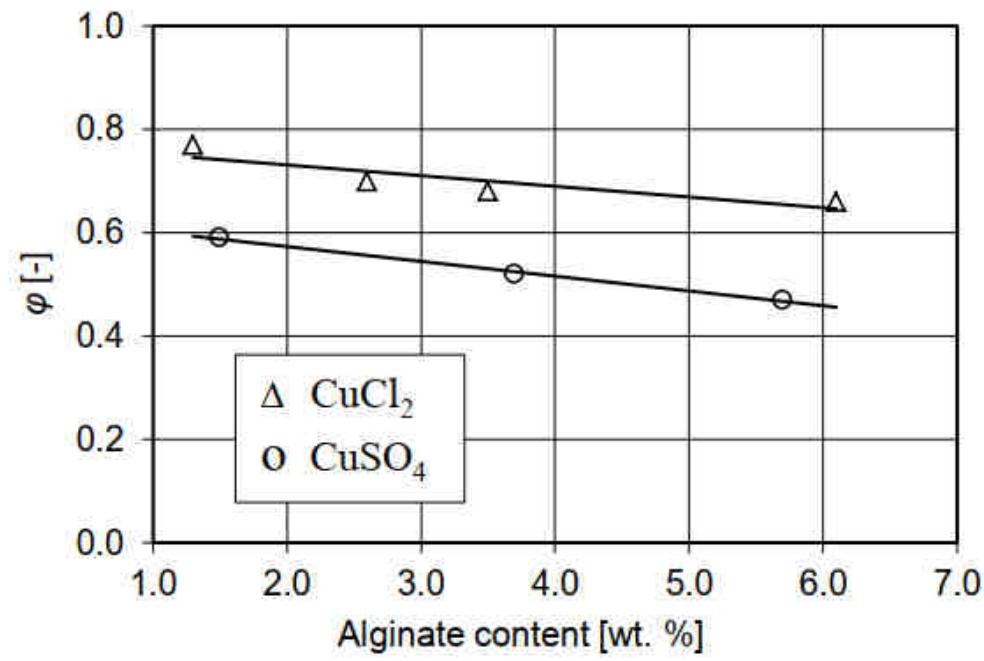

Fig. 4. Dependence of retardation coefficient on alginate content in beads for copper salts 
Values of effective diffusion coefficient for $\mathrm{Cu}$ (II) ions in the alginate beads according to literature

\begin{tabular}{|c|c|c|c|c|c|c|}
\hline \multirow{2}{*}{$\begin{array}{l}D_{e} \cdot 10^{9} \\
{\left[\mathrm{~m}^{2} / \mathrm{s}\right]}\end{array}$} & \multirow{2}{*}{$\begin{array}{l}\varphi^{1} \\
{[-]}\end{array}$} & \multicolumn{4}{|c|}{ Environmental conditions } & \multirow[b]{2}{*}{ Source } \\
\hline & & $\begin{array}{c}\mathbf{p H} \\
{[-]} \\
\end{array}$ & $\begin{array}{c}\text { Temp. } \\
{\left[{ }^{\circ} \mathrm{C}\right]}\end{array}$ & $\begin{array}{c}C_{i} \\
{\left[\mathrm{mg} / \mathrm{dm}^{3}\right]}\end{array}$ & Other & \\
\hline 0.98 & 1.31 & no data & 25 & 63.5 & $\begin{array}{l}\text { as calculated according to } \\
\text { SCM } \\
\text { sorbent: } 3 \% \text { alginate beads }\end{array}$ & [23] \\
\hline 1.08 & 1.45 & no data & 25 & 63.5 & $\begin{array}{l}\text { as calculated according to } \\
\text { LAM } \\
\text { sorbent: } 3 \% \text { alginate beads }\end{array}$ & [23] \\
\hline 1.2 & 1.61 & no data & no data & no data & $\begin{array}{l}\text { as calculated according to } \\
\text { SCM }\end{array}$ & [22] \\
\hline 0.45 & 0.60 & no data & no data & no data & $\begin{array}{l}\text { as calculated according to } \\
\text { LAM }\end{array}$ & [22] \\
\hline
\end{tabular}

${ }^{1}$ for $\mathrm{Cu}$ (II) ions at a temp. of $298 \mathrm{~K}$, as calculated from the Nernst formula: $D_{a q}=0.745 \cdot 10^{-9} \mathrm{~m}^{2} / \mathrm{s}$. According to the literature, $D_{a q}$ as found experimentally for copper(II) ions by different authors using different methods, is in the range $0.62-0.75 \cdot 10^{-9} \mathrm{~m}^{2} / \mathrm{s}[22]$

The values of $D_{e}$ and $\varphi$ were observed to decrease due to an increase in the alginate content in the sorbent beads. This is in agreement with the mechanism of the diffusion process taking place in porous carriers. The effective diffusion coefficients, as calculated for $\mathrm{CuCl}_{2}$, were considerably higher (nearly twice as high), in comparison with $\mathrm{CuSO}_{4}$.

The retardation coefficient $\varphi$ was also found to depend on the alginate content in the beads (Fig. 4). However, even though the values of $\varphi$ for $\mathrm{CuCl}_{2}$ were higher than those for $\mathrm{CuSO}_{4}$, the differences were not as pronounced as in the case of $D_{e}$. A more-than four-fold increase in the alginate content in the beads caused a decrease in the value of the retardation coefficient by merely $14 \%$ for copper(II) chloride, and by merely $20 \%$ for copper(II) sulfate.

Each $D_{e}$ value, obtained by the conductometric method is lower than the calculated diffusion coefficient in a highly dilute aqueous solution of a given salt. More often than not, the condition is not satisfied in literature reports (Table 2) using the conventional methods (SCM, LAM). Moreover, literature reports indicate a significant divergence between the values of $D_{e}$ obtained by SCM and those obtained by LAM. Those values of $D_{e}$ calculated by Lewandowski and Roe [23] using SCM are more than twice as high as the effective diffusion coefficient calculated by the LAM methods and reported by Chen et al. [22].

\section{Cadmium(II) salt diffusion}

Table 3 and Figure 5 show the results of calculation for cadmium chloride and cadmium sulfate. The effect of alginate content in the biosorbent beads on the effective diffusion coefficient $D_{e}$ and retardation coefficient $\varphi$ is shown.

All the values of $D_{e}$, obtained by the conductometric method, are lower than the calculated diffusion coefficients in a highly dilute solution of the given test salt, $D_{a q}$. As in the case of copper salts, the values of $D_{e}$ were observed to decrease for increased alginate contents in the sorbent beads. The effective diffusion coefficients, as calculated for cadmium chloride, were higher than those for cadmium sulfate but, when compared with copper salts, the differences were slightly less pronounced (for instance, $D_{e}$, calculated for $1.5 \%$ calcium alginate in the case of $\mathrm{CdSO}_{4}$, was $35 \%$ lower in comparison with the value obtained for $1.5 \%$ alginate and the diffusion of $\mathrm{CdCl}_{2}$ ). 
Dependence of effective diffusion coefficient on alginate content in beads for cadmium salts

\begin{tabular}{|c|c|c|c|}
\hline $\begin{array}{c}\text { Alginate content } \\
\text { in beads } \\
\text { [wt.\%] }\end{array}$ & $\begin{array}{c}\text { Effective diffusion } \\
\text { coefficient } \\
\boldsymbol{D}_{\boldsymbol{e}} \cdot \mathbf{1 0}^{\mathbf{9}}\left[\mathbf{m}^{2} / \mathrm{s}\right]\end{array}$ & $\begin{array}{c}\text { Correlation } \\
\text { coefficient } \\
\boldsymbol{r}^{\mathbf{2}}\end{array}$ & $\begin{array}{c}\text { Retardation coefficient } \\
\boldsymbol{f}=\frac{\boldsymbol{D}_{\boldsymbol{e}}}{\boldsymbol{D}_{a q}}\end{array}$ \\
\hline \multicolumn{4}{|c|}{$\mathrm{CdCl}_{2}\left(D_{a q}=1.26 \cdot 10^{-9} \mathrm{~m}^{2} / \mathrm{s}\right)$} \\
\hline 1.5 & 0.73 & 0.978 & 0.58 \\
\hline 3.7 & 0.67 & 0.989 & 0.53 \\
\hline 5.7 & 0.59 & 0.987 & 0.47 \\
\hline \multicolumn{4}{|c|}{$\mathrm{CdSO}_{4}\left(D_{a q}=0.86 \cdot 10^{-9} \mathrm{~m}^{2} / \mathrm{s}\right)$} \\
\hline 1.5 & 0.47 & 0.996 & 0.55 \\
\hline 3.7 & 0.40 & 0.995 & 0.46 \\
\hline 5.7 & 0.37 & 0.994 & 0.43 \\
\hline
\end{tabular}

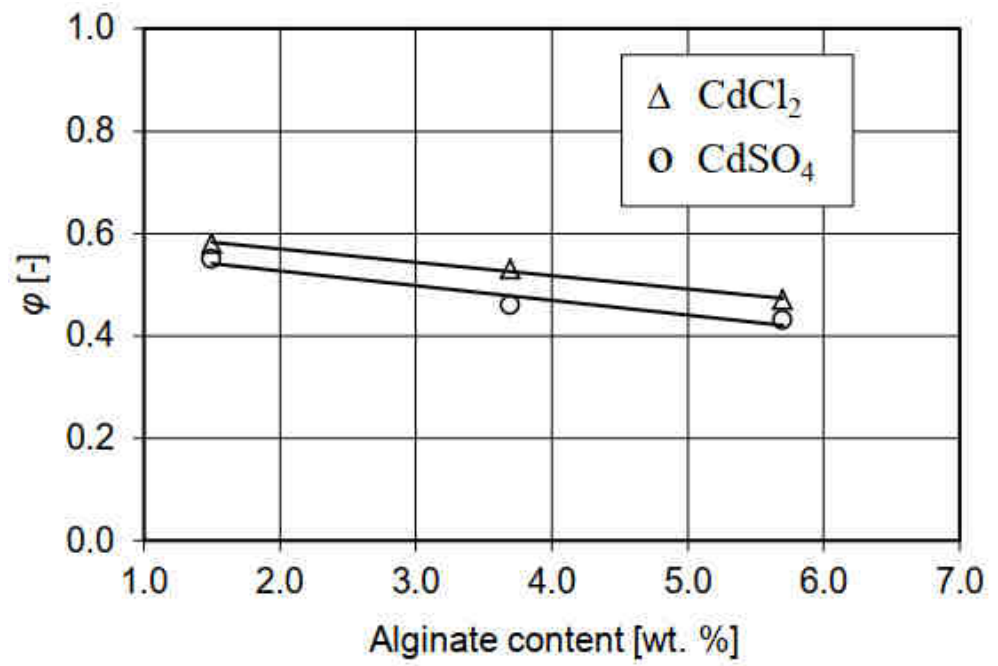

Fig. 5. Dependence of retardation coefficient on alginate content in beads for cadmium salts

Values of effective diffusion coefficient for $\mathrm{Cd}(\mathrm{II})$ ions in the alginate beads according to literature

\begin{tabular}{|c|c|c|c|c|c|c|}
\hline \multirow[b]{2}{*}{$\begin{array}{l}D_{e} \cdot 10^{9} \\
{\left[\mathrm{~m}^{2} / \mathrm{s}\right]}\end{array}$} & \multirow[b]{2}{*}{$\begin{array}{l}\varphi^{1} \\
{[-]}\end{array}$} & \multicolumn{4}{|c|}{ Environmental conditions } & \multirow[b]{2}{*}{ Source } \\
\hline & & $\begin{array}{c}\mathbf{p H} \\
{[-]}\end{array}$ & $\begin{array}{c}\text { Temp. } \\
{\left[{ }^{\circ} \mathbf{C}\right]}\end{array}$ & $\begin{array}{c}C_{i} \\
{\left[\mathrm{mg} / \mathrm{dm}^{3}\right]}\end{array}$ & Other & \\
\hline 0.30 & 0.42 & no data & no data & 100 & $\begin{array}{c}\text { as calculated according to } \\
\text { SCM sorbate: } \mathrm{CdSO}_{4} \\
\text { sorbent: } 2 \% \text { alginate beads }\end{array}$ & {$[32]$} \\
\hline 0.6 & 0.83 & 4.0 & no data & no data & no data & {$[35]$} \\
\hline 1.9 & 2.64 & 4.5 & 25 & 100 & $\begin{array}{l}\text { as calculated according to } \\
\text { LAM, sorbate: } \mathrm{CdSO}_{4} \\
\text { sorbent: } 2 \% \text { alginate beads }\end{array}$ & [9] \\
\hline 4.5 & 6.26 & 4.5 & 25 & 100 & $\begin{array}{c}\text { sorbate: } \mathrm{CdSO}_{4} \\
\text { sorbent: } 2 \% \text { alginate beads }\end{array}$ & [10] \\
\hline 0.0134 & 0.02 & 5.0 & 23 & 51 & sorbate: $\mathrm{Cd}\left(\mathrm{NO}_{3}\right)_{2}$ & [29] \\
\hline
\end{tabular}

${ }^{1}$ for Cd(II) ions at a temp. of $298 \mathrm{~K}: D_{a q}=0.719 \cdot 10^{-9} \mathrm{~m}^{2} / \mathrm{s}$ [35] 
Both the retardation coefficient $\varphi$ and the effective diffusion coefficient also depended on the alginate content in the beads; when the alginate content in the beads increased from 1.5 to $5.7 \%$, the value of $\varphi$ decreased by 19 and $22 \%$ for $\mathrm{CdCl}_{2}$ and $\mathrm{CdSO}_{4}$, respectively.

Also in this case, literature data (Table 4) indicated significant differences between the values of $D_{e}$, as obtained by the SCM [32] and LAM [9] methods.

\section{Zinc(II) salt diffusion}

Diffusion was tested for 3 zinc salts: chloride, sulfate and nitrate. Tables 5 shows the calculated values of the effective diffusion coefficient and the retardation coefficient for all of the zinc(II) salts tested.

Dependence of effective diffusion coefficient on alginate content in beads for zinc salts

Table 5

\begin{tabular}{|c|c|c|c|}
\hline $\begin{array}{l}\text { Alginate content } \\
\text { in beads } \\
\text { [wt. } \%]\end{array}$ & $\begin{array}{c}\text { Effective diffusion } \\
\text { coefficient } \\
D_{e} \cdot 10^{9}\left[\mathrm{~m}^{2} / \mathrm{s}\right]\end{array}$ & $\begin{array}{c}\text { Correlation } \\
\text { coefficient } \\
r^{2}\end{array}$ & $\begin{array}{c}\text { Retardation coefficient } \\
\qquad f=\frac{D_{e}}{D_{a q}}\end{array}$ \\
\hline \multicolumn{4}{|c|}{$\mathrm{ZnCl}_{2}\left(D_{a q}=1.25 \cdot 10^{-9} \mathrm{~m}^{2} / \mathrm{s}\right)$} \\
\hline 1.5 & 0.77 & 0.977 & 0.62 \\
\hline 3.7 & 0.73 & 0.982 & 0.59 \\
\hline 5.7 & 0.66 & 0.982 & 0.53 \\
\hline \multicolumn{4}{|c|}{$\mathrm{ZnSO}_{4}\left(D_{a q}=0.85 \cdot 10^{-9} \mathrm{~m}^{2} / \mathrm{s}\right)$} \\
\hline 1.5 & 0.44 & 0.962 & 0.52 \\
\hline 3.7 & 0.37 & 0.988 & 0.43 \\
\hline 5.7 & 0.24 & 0.967 & 0.28 \\
\hline \multicolumn{4}{|c|}{$\mathrm{Zn}\left(\mathrm{NO}_{3}\right)_{2}\left(D_{a q}=1.22 \cdot 10^{-9} \mathrm{~m}^{2} / \mathrm{s}\right)$} \\
\hline 1.5 & 0.84 & 0.985 & 0.69 \\
\hline 3.7 & 0.63 & 0.981 & 0.52 \\
\hline 5.7 & 0.50 & 0.966 & 0.41 \\
\hline
\end{tabular}

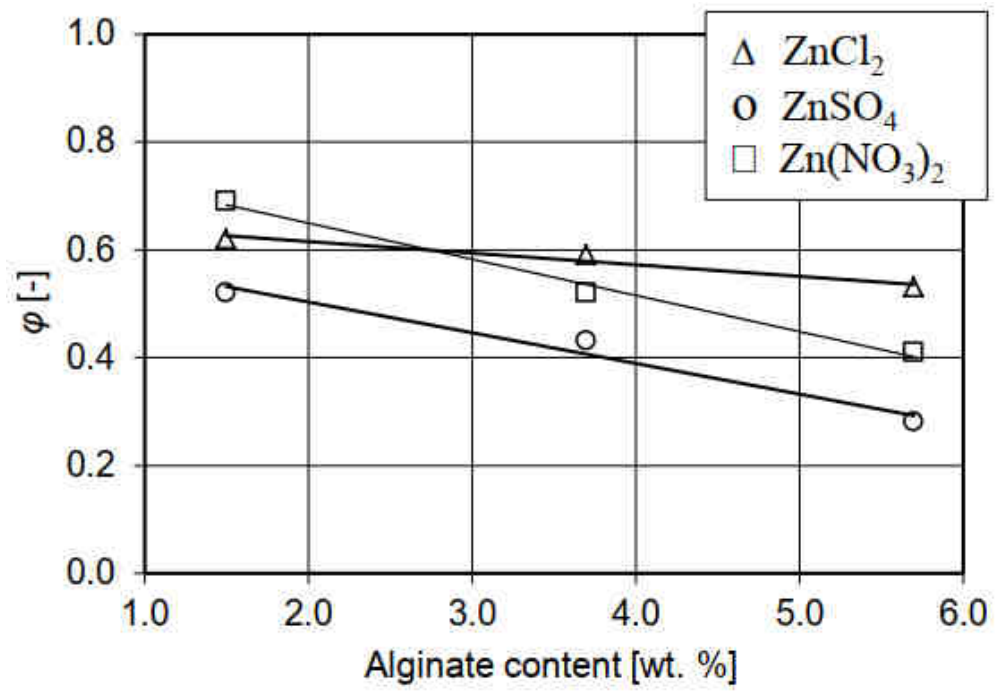

Fig. 6. Dependence of retardation coefficient on alginate content in beads for zinc salts 
No information has been found in the literature on the effective coefficient of diffusion of zinc ions in the alginate beads.

Also in this case, all of the values of $D_{e}$, as obtained by the conductometric method, are lower than the diffusion coefficients in a given, highly dilute test salt. The retardation coefficient (Fig. 6) and the effective diffusion coefficient were found to decrease with an increase in the alginate content in the beads. The lowest diffusion coefficients and the lowest retardation coefficients were obtained for zinc sulfate, the highest were obtained for zinc chloride.

\section{Diffusion of chromium nitrate}

The effective diffusion coefficients were calculated for chromium nitrate (Table 6). The beads with the lowest alginate content $(1.5 \mathrm{wt}$. \%), have been omitted from the calculations because they disintegrated in the course of the experiment.

Table 6

Dependence of effective diffusion coefficient on alginate content in beads for chromium salt

\begin{tabular}{|c|c|c|c|}
\hline $\begin{array}{c}\text { Alginate content } \\
\text { in beads } \\
{[\text { wt. \%] }}\end{array}$ & $\begin{array}{c}\text { Effective diffusion } \\
\text { coefficient } \\
\boldsymbol{D}_{\boldsymbol{e}} \cdot \mathbf{1 0}^{\mathbf{9}}\left[\mathbf{m}^{\mathbf{2}} / \mathrm{s}\right]\end{array}$ & $\begin{array}{c}\text { Correlation } \\
\text { coefficient } \\
\boldsymbol{r}^{\mathbf{2}}\end{array}$ & $\begin{array}{c}\text { Retardation coefficient } \\
\boldsymbol{f}=\frac{\boldsymbol{D}_{\boldsymbol{e}}}{\boldsymbol{D}_{\boldsymbol{a}}}\end{array}$ \\
\hline \multicolumn{4}{|c|}{$\left.\mathrm{Cr}^{\mathrm{NO}}\right)_{3}\left(D_{a q}=1.23 \cdot 10^{-9} \mathrm{~m}^{2} / \mathrm{s}\right)$} \\
\hline 3.7 & 0.31 & 0.966 & 0.25 \\
\hline 5.7 & 0.19 & 0.976 & 0.16 \\
\hline
\end{tabular}

Values of effective diffusion coefficient for $\mathrm{Cr}(\mathrm{III})$ ions in the alginate beads according to literature

\begin{tabular}{|c|c|c|c|c|c|c|}
\hline \multirow{2}{*}{$\begin{array}{c}\boldsymbol{D}_{\boldsymbol{e}} \cdot \mathbf{1 0}^{\mathbf{9}} \\
{\left[\mathbf{m}^{\mathbf{2}} / \mathbf{s}\right]}\end{array}$} & $\begin{array}{c}\boldsymbol{\varphi}^{\mathbf{1}} \\
{[-]}\end{array}$ & $\begin{array}{c}\mathbf{p H} \\
{[-]}\end{array}$ & $\begin{array}{c}\text { Temp. } \\
{\left[{ }^{\circ} \mathbf{C}\right]}\end{array}$ & $\boldsymbol{C}_{\boldsymbol{i}}[\mathbf{m m o l}]$ & Other & Source \\
\hline 2.39 & 4.02 & $\begin{array}{c}\text { no } \\
\text { data }\end{array}$ & 10 & 0.2 & $\begin{array}{c}\text { as calculated according to SCM } \\
\text { sorbent: } 6.2 \% \text { beads }\end{array}$ & [30] \\
\hline 0.47 & 0.79 & $\begin{array}{c}\text { no } \\
\text { data }\end{array}$ & 10 & 0.2 & $\begin{array}{c}\text { as calculated according to LAM } \\
\text { sorbent: } 6.2 \% \text { beads }\end{array}$ & \\
\hline
\end{tabular}

${ }^{1}$ for $\mathrm{Cr}(\mathrm{III})$ ions at a temp. of $298 \mathrm{~K}$ as calculated from the Nernst formula: $D_{a q}=0.594 \cdot 10^{-9} \mathrm{~m}^{2} / \mathrm{s}$

The results for the bead types tested by the authors are comparable with those obtained for salts of the other metals tested; this means that an increase in the alginate content in the beads leads to a decrease in the values of $D_{e}$ and $\varphi$.

Once more, a significant divergence is observed between the results for the SCM and LAM methods (Table 7). The differences are best visible in the case of chromium: the value of $D_{e}$ obtained by SCM was nearly 5-times as high as that contained by LAM, even though same conditions were applied.

\section{Diffusion of lead nitrate}

Lead nitrate was used for the tests because both lead sulfate and lead chloride are hard to dissolve in water. The results of calculation are shown in Table 8. For lead nitrate, the retardation coefficient decreases with an increase in the alginate content in the beads, however, its decrease is not very pronounced because the alginate beads, of which the 
alginate content is nearly 4-times as high, have a retardation coefficient of just more than $13 \%$ lower (down from 0.52 to 0.45 ).

Table 8

Dependence of the effective retardation coefficient on alginate content in the beads for lead salt

\begin{tabular}{|c|c|c|c|}
\hline $\begin{array}{c}\text { Alginate content } \\
\text { in beads } \\
\text { [wt. } \%]\end{array}$ & $\begin{array}{c}\text { Effective diffusion } \\
\text { coefficient } \\
\boldsymbol{D}_{\boldsymbol{e}} \cdot \mathbf{1 0} \mathbf{0}^{\mathbf{9}}\left[\mathbf{m}^{2} / \mathrm{s}\right]\end{array}$ & $\begin{array}{c}\text { Correlation } \\
\text { coefficient } \\
\boldsymbol{r}^{\mathbf{2}}\end{array}$ & $\begin{array}{c}\text { Retardation coefficient } \\
\boldsymbol{f}=\frac{\boldsymbol{D}_{\boldsymbol{e}}}{\boldsymbol{D}_{a q}}\end{array}$ \\
\hline \multicolumn{4}{|c|}{$\mathrm{Pb}_{\left(\mathrm{NO}_{3}\right)_{2}\left(D_{a q}=1.41 \cdot 10^{-9} \mathrm{~m}^{2} / \mathrm{s}\right)}$} \\
\hline 1.5 & 0.74 & 0.980 & 0.52 \\
\hline 3.7 & 0.70 & 0.994 & 0.49 \\
\hline 5.7 & 0.64 & 0.991 & 0.45 \\
\hline
\end{tabular}

In the literature [33] the values of the diffusivity coefficient were found several orders of magnitude lower than the self-diffusivity of $\mathrm{Pb}$ (II) $\left(D_{a q}=1.41 \cdot 10^{-9} \mathrm{~m}^{2} / \mathrm{s}\right)$ and is $D_{e}=0.72 \cdot 10^{-12} \mathrm{~m}^{2} / \mathrm{s}$ for air-dried beads (as calculated according to $\mathrm{SCM}, \mathrm{pH}=4$, temp. $=25^{\circ} \mathrm{C}, C_{i}=100 \mathrm{mg} / \mathrm{dm}^{3}$ ). This confirms that the resistance to intraparticle diffusion plays a significant role in the control of uptake kinetics.

For all tested metal salts the value of the effective diffusion coefficient is affected by the metal salt anion. In the case of sulfates, the highest values of $D_{e}$ were obtained for the $\mathrm{Cu}$ salts, the lowest - for the $\mathrm{Zn}$ sulfate. For the chlorides, the highest values of $D_{e}$ were obtained also for $\mathrm{Cu}$, and the lowest - for $\mathrm{Cd}$; the values of $D_{e}$ for $\mathrm{Zn}$ were not much higher than those calculated for $\mathrm{Cd}$. For the nitrate salts, the lowest diffusion coefficients were those for chromium. Much higher values of $D_{e}$ were recorded for zinc nitrate and the highest (with the exception of the $1.5 \%$ alginate beads), were those for lead nitrate.

\section{Conclusions}

The experimental results clearly indicate a decrease in the values of $D_{e}$, caused by an increase in the alginate content in the sorbent beads. This is in agreement with the mechanism of the diffusion process taking place in porous carriers. Good agreement between the experimental data and the mathematical model was obtained, as shown by the high values of correlation coefficients.

The value of the effective diffusion coefficient is affected by the metal salt anion, therefore, it should also be taken into account in the calculations.

All the values of $D_{e}$, obtained by the conductometric method, are lower than the calculated diffusion coefficients in a given, highly dilute salt. More often than not, the condition is not satisfied in literature reports, especially in calculations by conventional methods (SCM, LAM).

The conductometric method is simple and it provides good results in calculating the effective diffusion coefficients for heavy metals in alginate sorbents.

\section{References}

[1] Biegańska M, Cierpiszewski R. Utilization of agricultural and industrial wastes for metal removal from aqueous solutions. Polish J Chem Technol. 2011;13,1:20-22. DOI: 10.2478/V10026-011-0004.

[2] Argun ME, Dursun S, Ozdemir C, Karatas M. Heavy metal adsorption by modified oak sawdust: thermodynamics and kinetics. J Hazard Mater. 2007;141:77-85. DOI: 10.1016/J.Jhazmat.2006.06.095. 
[3] Rozada F, Otero M, Morán A, García AI. Adsorption of heavy metals onto sewage sludge-derived materials. Bioresour Technol. 2008;99:6332-6338. DOI: 10.1016/j.biortech.2007.12.015.

[4] Meena AK, Kadirvelu K, Mishra GK, Rajagopal C, Nagar PN. Adsorption of Pb(II) and Cd(II) metal ions from aqueous solutions by mustard husk. J Hazard Mater. 2008;150:619-625. DOI: 10.1016/j.jhazmat.2007.05.011.

[5] Chand R, Narimura K, Kawakita H, Ohto K, Watari T, Inoue K. Grape waste as a biosorbents for removing Cr(VI) from aqueous solution. J Hazard Mater. 2009;163:245-250. DOI: 10.1016/j.jhazmat.2008.06.084.

[6] Dhakal RP, Ghimire KN, Inoue K. Adsorptive separation of heavy metals from an aquatic environment using orange waste. Hydrometallurgy. 2005;79:182-190. DOI: 10.1016/j.hydromet.2005.06.007.

[7] Ghimire KN, Inoue K, Yamaguchi H, Makino K, Miyajima T. Adsorptive separation of arsenate and aresnite anions from aqueous medium by using orange waste. Water Res. 2003;37:4945-4953. DOI: 10.1016/j.watres.2003.08.029.

[8] Rincon J, Gonzalez F, Ballester A, Blazquez ML, Munoz JA. Biosorption of heavy metals by chemically activated alga Fucus Vesiculosus. J Chem Technol Biotechnol. 2005;80:1403-1407. DOI: 10.1002/jctb.1342.

[9] Papageorgiou SK, Katsaros FK, Kouvelos EP, Nolan JW, Le Deit H, Kanellopoulos NK. Heavy metal sorption by calcium alginate beads from Laminaria Digitata. J Hazard Mater. 2006;B137:1765-1772. DOI: 10.1016/j.jhazmat.2006.05.017.

[10] Papageorgiou SK, Kouvelos EP, Katsaros FK. Calcium alginate beads from Laminaria digitata for the removal of $\mathrm{Cu}^{2+}$ and $\mathrm{Cd}^{2+}$ from dilute aqueous metal solutions. Desalination. 2008;224:293-306. DOI: 10.1016/j.desal.2007.06.011.

[11] Lai Y-L, Annadurai G, Huang F-H, Lee J-F. Biosorption of Zn(II) on the different Ca-alginate beads from aqueous solution. Bioresour Technol. 2008; 99(14):6480-6487. DOI: 10.1016/j.biortech.2007.11.041.

[12] Grimm A, Zanzi R, Björnbom E, Cukierman AL. Comparison of different types of biomasses for copper biosorption. Bioresour Technol. 2008;99:2559-2565. DOI: 10.1016/j.biortech.2007.04.036.

[13] Chojnacka K. Biosorption and bioaccumulation - The prospects for practical applications. Environ Int. 2010;36:299-307. DOI: 10.1016/j.envint.2009.12.001.

[14] Rajfur M, Kłos A, Wacławek M. Sorption of copper(II) ions in the biomass of alga Spirogyra sp. Bioelectrochemistry. 2012;87:65-70. DOI: 10.1016/j.bioelechem.2011.12.007.

[15] Huang D, Wang W, Wang A. Removal of $\mathrm{Cu}^{2+}$ and $\mathrm{Zn}^{2+}$ ions from aqueous solution using sodium alginate and attapulgite composite hydrogels. Adsorption Sci Technol. 2013;31(7):611-624. DOI: 10.1260/0263-6174.31.7.611.

[16] Srivastava S, Agrawal SB, Mondal MK. A review on progress of heavy metal removal using adsorbents of microbial and plant origin. Environ Sci Pollut Res. 2015;22:15386-15415. DOI: 10.1007/s11356-015-5278-9.

[17] Jain CK, Malik DS, Yadav AK. Applicability of plant based biosorbents in the removal of heavy metals: a review. Environ Process. 2016;3:495-523. DOI: 10.1007/s40710-016-0143-5.

[18] Khan TA, Mukhlif AA, Khan EA, Sharma DK. Isotherm and kinetics modeling of $\mathrm{Pb}$ (II) and Cd(II) adsorptive uptake from aqueous solution by chemically modified green algal biomass. Model Earth Syst Environ. 2016;2:117. DOI: 10.1007/s40808-016-0157-z.

[19] Yildız S. Kinetic and isotherm analysis of $\mathrm{Cu}$ (II) adsorption onto almond shell (Prunus dulcis). Ecol Chem Eng S. 2017;24(1):87-106. DOI: 10.1515/eces-2017-0007.

[20] Cheng J, Yin W, Chang Z, Lundholm N, Jiang Z. Biosorption capacity and kinetics of cadmium(II) on live and dead Chlorella vulgaris. J Appl Phycol. 2017;29:211-221. DOI: 10.1007/s10811-016-0916-2.

[21] Kłos A. Determination of sorption properties of heavy metals in various biosorbents. Ecol Chem Eng S. 2018;25(2):201-216. DOI: 10.1515/eces-2018-0013.

[22] Chen D, Lewandowski Z, Roe F, Surapaneni P. Diffusivity of $\mathrm{Cu}^{2+}$ in calcium alginate gel beads. Biotechnol Bioeng. 1993;41:755-760. DOI: 10.1002/bit.260430212.

[23] Lewandowski Z, Roe F. Communication to the editor. Diffusivity of $\mathrm{Cu}^{2+}$ in calcium alginate gel beads: recalculation. Biotechnol Bioeng. 1994;43:186-187. DOI: 10.1002/bit.260430213.

[24] Konishi Y, Shimaoka J, Asai S. Sorption of rare-earth ions on biopolymer gel beads of alginic acid. Reactive Functional Polymers. 1998;36:197-206.

[25] Ibanez JP, Umetsu Y. Uptake of copper from extremely dilute solutions by alginate sorbent material: an alternative for enviromental control. Proc Copper 99-Cobre 99 Int Environ Conf. 1999; 387-397. www.jglobal.jst.go.jp/en/detail?JGLOBAL_ID=200902146055619979\&rel=0.

[26] Veglio F, Esposito A, Reverberi AP. Copper adsorption on calcium alginate beads: equilibrium pH-related models. Hydrometallurgy. 2002;65:43-57. DOI: 10.1016/S0304-386X(02)00064-6.

[27] Kwiatkowska-Marks S, Wójcik M, Kopiński L. Biosorption of heavy metals on alginate beads. Przem Chem. 2011;90(10):1924-1930. www.bwmeta1.element.baztech-d10e4e16-2e7d-4d6d-a346-a7b1ca859142. 
[28] Arica MY, Bayramoglu G, Yilmaz M, Bektas S, Genc O. Biosorption of $\mathrm{Hg}^{2+}, \mathrm{Cd}^{2+}$, and $\mathrm{Zn}^{2+}$ by ca-alginate and immobilized wood-rotting fungus Funalia Trogii. J Hazard Mater. 2004;B109:191-199. DOI: 10.1016/j.jhazmat.2004.03.017.

[29] Apel ML, Torma AE. Determination of kinetics and diffusion coefficients of metal sorption on Ca-alginate beads. Canad J Chem Eng. 1993;71:652-656. DOI: 10.1002/cjce.5450710419.

[30] Araujo MM, Teixeira JA. Trivalent chromium sorption on alginate beads. Int Biodeterioration Biodegrad. 1997;40:63-74. DOI: 10.1016/s0964-8305(97)00064-4.

[31] Kwiatkowska-Marks S, Kopiński L, Wójcik M. Conductometric determination of the effective copper ion diffusion coefficient in alginate beads. Inż Aparat Chemiczna. 2011;50,6:9-11. http://inzynieria-aparaturachemiczna.pl/rok-2011-nr-6/.

[32] Klimiuk E, Kuczajowska-Zadrożna M. The effect of poly(vinyl alcohol) on cadmium adsorption and desorption from alginate adsorbents. Polish J Environ Stud. 2002;11,4:375-384. www.agro.icm.edu.pl/agro/element/bwmeta1.element.agro-article-e21e2198-9aae-412a-be4e1804db34c293?q=bwmeta1 .element.agro-number-ddd87f36-30f6-4d53-aaca-2372e24ee9ee.

[33] Wang S, Vincent T, Faur C, Guibal E. Alginate and algal-based beads for the sorption of metal cations: $\mathrm{Cu}(\mathrm{II})$ and $\mathrm{Pb}(\mathrm{II})$. Int J Mol Sci. 2016;17:1453. DOI: 10.3390/ijms17091453.

[34] Arnaud J-P, Lacroix C, Castaigne F. Counterdiffusion of lactose and lactic acid in $\kappa$-carrageenan/locust bean gum gel beads with or without entrapped lactic acid bacteria. Enzyme Microbial Technol. 1992;14:715-724. DOI: 10.1016/0141-0229(92)90111-Z.

[35] Volesky B. Biosorption process simulation tools. Hydrometallurgy. 2003;71:179-190. DOI: 10.1016/S0304-386X(03)00155-5. 